Materiales de Construcción

Vol. 69, Issue 336, October-December 2019, e204

ISSN-L: 0465-2746

https://doi.org/10.3989/mc.2019.05719

\title{
Study of the suitability of a new structural concrete manufactured with carbon fiber reinforced lightweight aggregates sintered from wastes
}

\author{
J.M. Moreno-Maroto ${ }^{\mathrm{a}}$, A.L. Beaucour ${ }^{\mathrm{b}}$, B. González-Corrochano ${ }^{\mathrm{c}}, \mathrm{J}_{\text {. Alonso-Azcárate }}^{\mathrm{c}} \bowtie$ \\ a. Department of Chemical, Environmental and Materials Engineering, Higher Polytechnic School of Linares, \\ University of Jaen (Spain) \\ b. Laboratoire de Mécanique \& Matériaux du Génie Civil, University of Cergy-Pontoise (France) \\ c. Department of Physical Chemistry, Faculty of Environmental Sciences and Biochemistry, \\ University of Castilla-La Mancha, Toledo (Spain) \\ \jacinto.alonso@uclm.es
}

Received 17 April 2019

Accepted 10 July 2019

Available on line 1 October 2019

\begin{abstract}
The suitability of three new lightweight aggregates containing carbon fiber residues (CAs) as components in structural lightweight concrete has been studied. Prismatic concrete specimens were prepared using these CAs as a coarse fraction. Additional specimens of normal-weight aggregate, commercial lightweight aggregate and mortar were prepared for comparison. The CA-concrete samples (CACs) have yielded compressive strength values between 35 and $55 \mathrm{MPa}$ as well as low density and thermal conductivity results. Furthermore, the CACs have displayed the highest ratios of mechanical strength over density and the thermal conductivity, which means that there is a better balance between their mechanical and physical properties than in the other samples studied. These results indicate that the new CAs could have great potential for use in structural lightweight concrete, also complying with the principles of the Circular Economy.
\end{abstract}

KEYWORDS: Aggregate; Concrete; Fibre reinforcement; Waste treatment; Mechanical properties.

Citation/Citar como: Moreno-Maroto, J.M.; Beaucour, A.L; González-Corrochano, B.; Alonso-Azcárate, J. (2019) Study of the suitability of a new structural concrete manufactured with carbon fiber reinforced lightweight aggregates sintered from wastes. Mater. Construcc. 69 [336], e204 https://doi.org/10.3989/mc.2019.05719

RESUMEN: Estudio de la idoneidad de un nuevo hormigón estructural fabricado con áridos ligeros reforzados con fibra de carbono sinterizados a partir de residuos. Este estudio pretende comprobar la idoneidad de unos novedosos áridos ligeros sinterizados con residuos de fibra de carbono (CAs) en la fabricación de hormigón ligero estructural. Se prepararon probetas prismáticas de hormigón, utilizando estos CAs como fracción gruesa, comparándose a su vez con probetas fabricadas con un árido convencional, un árido ligero comercial y mortero. Las muestras de hormigón con los áridos CA (en adelante CAC) han dado lugar a valores de resistencia a compresión entre 35 y $55 \mathrm{MPa}$, así como a resultados bajos de densidad y conductividad térmica, mostrando además las ratios más altas al relacionar estos tres parámetros. Esto indicaría por tanto un mejor equilibrio entre las propiedades mecánicas y físicas que los obtenidos en las otras muestras estudiadas. Estos resultados apuntan a que los nuevos CAs podrían tener un gran potencial para su uso en hormigón ligero estructural, cumpliendo además los principios de la Economía Circular.

Palabras clave: Árido; Hormigón; Refuerzo de fibras; Tratamiento de residuos; Propiedades mecánicas.

ORCID ID: J.M. Moreno-Maroto (http://orcid.org/0000-0002-6312-1075); A.L. Beaucour (https://orcid.org/00000001-7573-0997); B. González-Corrochano (https://orcid.org/0000-0001-9591-4347); J. Alonso-Azcárate (http://orcid. org/0000-0003-2187-9360)

Copyright: (C) 2019 CSIC. This is an open-access article distributed under the terms of the Creative Commons Attribution 4.0 International (CC BY 4.0) License. 


\section{INTRODUCTION}

Concrete made from lightweight aggregate (LWA) typically has reduced unit weight, better thermal and sound insulation as well as improved fire resistance (1). In accordance with the EN-13055-1 standard (2), LWAs are those aggregates that present a loose bulk density $\left(\rho_{\mathrm{B}}\right)$ less than $1.20 \mathrm{~g} / \mathrm{cm}^{3}$ or a particle density $\left(\rho_{\mathrm{A}}\right)$ not exceeding $2.00 \mathrm{~g} / \mathrm{cm}^{3}$. Therefore, a concrete is labeled as lightweight concrete (hereafter, LWAC) when it is totally or partially composed of LWA, giving rise to a low dry density between 2.0 and $0.8 \mathrm{~g} / \mathrm{cm}^{3}$ (3). Likewise, according to the Spanish guidelines included in EHE-08 (4), a LWAC would be suitable for use in structural purposes as long as its minimum characteristic compressive strength at 28 days is $15 \mathrm{MPa}$ in mass or $25 \mathrm{MPa}$ in reinforced or prestressed layout.

Although the use of LWA in construction goes back far in antiquity (e.g. Pantheon in Rome (5)), the most conventional industrial process to produce LWAs was not settled until the early 1900s. This was mainly based on firing clay and shale in rotary kilns at high temperatures (1) and it is still the most followed procedure to synthesize LWAs. Despite this, the new environmental policies adopted by developed countries have led to changes in industrial protocols, many of them related to the use of wastes as new raw materials (6). The LWA sector is not indifferent to this, as reflected by the numerous studies focused on the manufacturing of LWAs from a wide range of wastes and its successful application in concrete (7). Some examples are: the reappraisal of Lynn et al. (8) shows the potential usefulness of sewage sludge ash in the manufacture of LWAs and LWAC; Wainwright and Cresswell (9) sintered combustion ashes into LWAs, whose replacement as a coarse fraction in LWAC resulted in compressive strengths between 33 and $51 \mathrm{MPa}$; De Gennaro et al. (10) used zeolite-rich rocks and SiC-rich porcelain sludge to obtain LWAs and structural LWAC, while Mueller et al. (11) manufactured LWAs and structural LWAC using recycled masonry rubble as raw materials.

In a previous study, the authors developed a new type of LWAs containing carbon fiber (12), here called CAs. In order to be as environmentally friendly as possible, three different wastes were used as raw materials: an ornamental rock sludge, an unmarketable sepiolite and carbon fiber remnants from an aeronautic parts factory. The methodology followed in that investigation (which is further elaborated in the section on Materials and Methods), included several steps, from the initial milling of the raw materials, to the shaping of the pellets and the firing of them at different temperatures and dwell times in a rotary kiln. The addition of carbon fiber in the mixtures not only promoted the bloating effect required to achieve a lightweight porous structure, but also improved the mechanical strength. This mechanical enhancement was attributed to the role of carbon fiber in the formation of a thick and stiff shell, as well as a significant sintering effect in the core. In addition, due to their refractoriness (13), many carbon fiber particles were able to withstand the firing stage completely, so that they appeared embedded in the inner structure, exerting an additional mechanical reinforcement (12).

Improvements in mechanical strength, temperature sensitivity and electrical resistance when carbon fiber is integrated into the concrete mortar matrix are well documented (14-20). However, concrete in which the coarse aggregates contain carbon fiber inside their structure has never been researched. Thus, the aim of the present investigation is to check the applicability of the new CAs as aggregates in structural concrete. To do this, three CAs will be used as coarse components: two varieties manufactured at 1125 and $1150{ }^{\circ} \mathrm{C}$, which have been selected from the authors' original study for their desirable mechanical strength and lightness respectively (12), and a new one, which has been sintered with the same material but at an intermediate temperature of $1140{ }^{\circ} \mathrm{C}$. The fresh and cast concrete will be undergone a comprehensive set of physical and mechanical tests, so that the degree of improvement reached when the new CAs are applied in concrete will be discerned by comparing the test results with those obtained when using a normal aggregate and a commercial lightweight aggregate.

\section{MATERIALS AND METHODS}

\subsection{Manufacturing of CAs}

Although the protocol followed for the manufacturing of the CAs is explained in more detail in (12), the general steps can be described as follows:

The CAs were manufactured using three different wastes as raw materials: the main mineral phase was comprised of $90 \%(\mathrm{w} / \mathrm{w})$ of a residual granitemarble sludge plus $10 \%(\mathrm{w} / \mathrm{w})$ of a sepiolite clay rejected in plant. The suppliers of these two residues were the companies Gramacen, S.L. (Cuerva, Spain) and Tolsa, S.A. (Vallecas, Spain), respectively. Both materials were oven-dried at $60^{\circ} \mathrm{C}$ and grinded to a grain size of $<200 \mu \mathrm{m}$ (21) using a Restch ${ }^{\circledR}$ SK 100/C Spezialstahl arm mill. A proportion of $2.5 \%(\mathrm{w} / \mathrm{w})$ of powdered carbon fiber was added into the mineral phase. The carbon fiber residue was supplied by ICSA-Aernnova (Toledo, Spain) in the form of stiff sheets from the cutting of AS4 and IM7 carbon fiber fabric, which were embedded in a hardened HexPly ${ }^{\circledR} 8552$ epoxy matrix. Therefore, before its addition to the mixture, the carbon fiber material was first cut into small pieces and then grinded into a powder of less than $500 \mu \mathrm{m}$ using the same mill indicated above. These three components 
were homogeneously blended and then kneaded with about $40 \%$ distilled water, so that the material was perfectly malleable. Relying on GonzálezCorrochano et al. (22), after $72 \mathrm{~h}$ of curing, the paste was extruded through a Nannetti ${ }^{\circledR}$ pneumatic extruder and subsequently shaped by hand into spherical pellets of around $9.3 \mathrm{~mm}$. Once the pellets were dried, first at room temperature for $48 \mathrm{~h}$ and then in oven for another $48 \mathrm{~h}$, they were sintered in a Nannetti ${ }^{\circledR}$ TOR-R 120-14 laboratory-scale tubular rotary kiln at a rotation speed of $2.5 \mathrm{rpm}$ for $4 \mathrm{~min}$. Three different firing temperatures were applied: 1125,1140 and $1150^{\circ} \mathrm{C}$, which allowed three different CAs to be obtained: CA25 (Figure 1a), CA40 (Figure 1b) and CA50 (Figure 1c), respectively. The firing conditions of 1125 and $1150^{\circ} \mathrm{C}$ and the characteristics of their respective LWAs, CA25 and CA50, were already reported in (12), while the temperature of $1140^{\circ} \mathrm{C}$ for CA40 has been implemented as a new variable for the present study.

\subsection{Materials used for the concrete}

Apart from the three new CAs mentioned above, two commercial coarse aggregates were also used for comparison: a commercial expanded clay aggregate (here simply called AX) as well as a normal weight aggregate extracted from the River Seine in Achères (Paris, France). AX is an expanded clay LWA with a rounded shape and a nominal particle size of $4 / 10$, which is intended for structural concrete. For its part, the normal aggregate (designated in this study as NA) contains mainly flint and limestone particles of irregular shape in a ratio of approximately 70:30. Both AX and NA were sieved, so that only the $8 / 10 \mathrm{~mm}$ fraction was selected, discarding the others to obtain the same particle size distribution as that of the new carbon fiber aggregates. The external appearance of both aggregates is depicted in Figure 1 d,e. The fine aggregate was a 0/4 sand also extracted from the River Seine (Paris, France), while the type of cement was Portland CEM I 52.5.

\subsection{Characterization of the aggregates}

The loose bulk density $\left(\rho_{\mathrm{b}}\right.$, in $\left.\mathrm{g} / \mathrm{cm}^{3}\right)$ of the aggregates was determined according to EN-1097-3 (23), while the particle density $\left(\rho_{\mathrm{a}}\right.$, in $\left.\mathrm{g} / \mathrm{cm}^{3}\right)$, the skeleton density $\left(\rho_{\mathrm{S}}\right.$, in $\left.\mathrm{g} / \mathrm{cm}^{3}\right)$, the saturated-surface dried density $\left(\rho_{\mathrm{ssd}}\right.$, in $\left.\mathrm{g} / \mathrm{cm}^{3}\right)$ and the percentage of water absorption after $24 \mathrm{~h}$ immersion (WA) were measured with a water pycnometer based on the standard EN-1097-6 and its Annex C (24). The relative density of the aggregate matrix $\left(\rho_{\text {matrix }}\right.$, in $\left.\mathrm{g} / \mathrm{cm}^{3}\right)$ was obtained with an AccuPyc ${ }^{\mathrm{TM}} 1330$ helium pycnometer from three granules milled to $<53 \mu \mathrm{m}$ with an agate mortar (25). The percentages of total, open and closed porosity of the aggregates $\left(P_{\mathrm{T}}, P_{\mathrm{O}}\right.$ and $P_{\mathrm{C}}$ respectively) were calculated from the results of $\rho_{\mathrm{a}}, \rho_{\mathrm{S}}$ and $\rho_{\text {matrix }}$, as indicated by Bernhardt et al. (25) and De Santiago Buey and Raya García (26). The void percentage $(H)$ was determined based on the results of $\rho_{\mathrm{B}}$ and $\rho_{\text {matrix }}$ according to MorenoMaroto et al. $(12,27)$. The crushing strength $(S$, in $\mathrm{MPa}$ ) of individual coarse aggregates was measured (a)

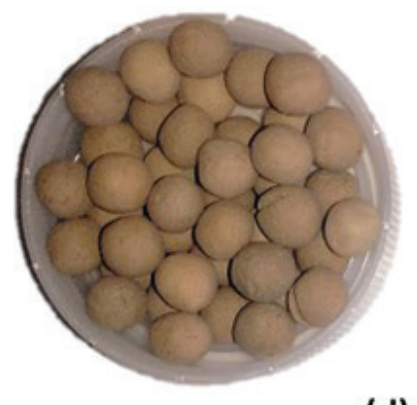

(d)

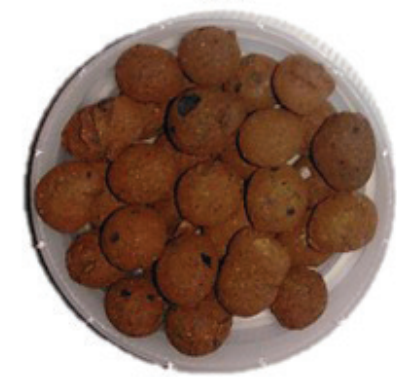

(b)

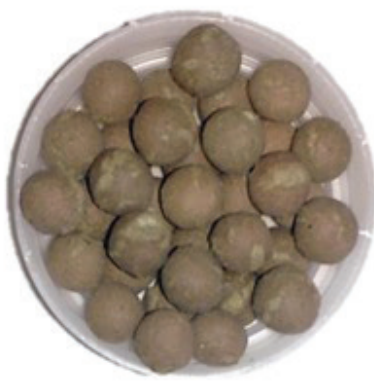

(e)

(e) (c)

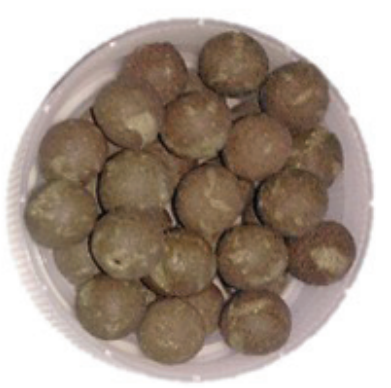

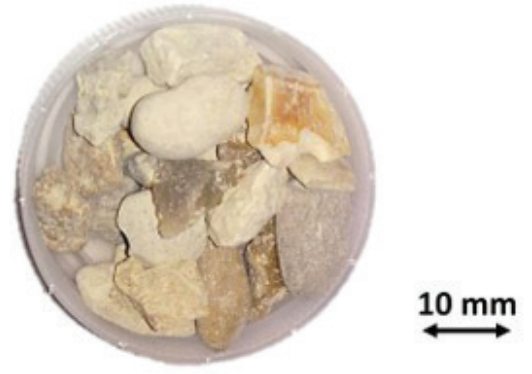

Figure 1. Coarse aggregates used in this study: (a) CA25, (b) CA40, (c) CA50, (d) AX, (e) NA. 
with a Nannetti ${ }^{\circledR}$ FM 96 press and calculated as indicated by Li et al. (28) and Yashima et al. (29) [1]:

$$
S=\left(2.8 \times \mathrm{F}_{\mathrm{c}}\right) /\left(\pi \times \mathrm{D}^{2}\right)
$$

where,

$\mathrm{F}_{\mathrm{c}}$ is the force measured in $\mathrm{N}$ when the failure occurs

$\mathrm{D}$ is the distance between the load points ( $\mathrm{mm}$ ) when contacting the aggregate (i.e. $\mathrm{D}$ is the aggregate diameter)

The final value of $S$ is the average of 25 data.

All the results related to the parameters measured in the aggregates are summarized in Table 1.

\subsection{Concrete mix proportions}

The proportion of coarse aggregate and sand was 50:50 in all the cases, and their sum represented the $67.3 \%(\mathrm{v} / \mathrm{v})$ of the total concrete mixture, with the remaining $32.7 \%(\mathrm{v} / \mathrm{v})$ corresponding to water plus cement. Two different water/cement ratios (w/c, expressed in mass ratio) were studied: 0.45 and 0.55 . Thus, a total of 10 concrete samples were obtained. In addition, 2 mortars (hereinafter referred to as MT) were prepared using the same formulations as those for concretes but without using coarse aggregates.

\subsection{Concrete manufacturing and testing}

The LWAs were immersed for $24 \mathrm{~h}$ in water before preparing the concrete specimens. The amount of LWA to be used in each mixture was calculated taking into account the data of $\rho_{\text {ssd }}$, so that the LWAs were saturated in water but with their surface dried out with a cloth. In the cases of both the sand and the normal coarse aggregate, the material was added containing all its moisture, correcting the available surface water. All the components were homogeneously blended by hand until a homogeneous mixture was obtained. The workability of the fresh concrete was measured by means of an LCPC workability-meter as described in the NF P18-452 standard (30), which determines the time $\left(t_{F}\right.$, in $\left.s\right)$ required by the concrete to flow a certain distance under vibration conditions (31). Prismatic specimens of $40 \times 40 \times 160 \mathrm{~mm}^{3}$ were prepared in triplicate for each type of concrete. The fresh concrete was poured into two layers, each of which was compacted on a vibrating table until the release of bubbles ceased. The concrete samples were kept in their moulds for $24 \mathrm{~h}$, covering their surface with a metal plate to avoid water loss. After $24 \mathrm{~h}$, all the specimens were demoulded and immersed in water for curing. After 28 days of curing, the wet density $\left(\rho_{\text {wet }}\right.$, in $\left.\mathrm{g} / \mathrm{cm}^{3}\right)$ of the samples was measured using a hydrostatic balance. Afterwards the specimens were taken from the water to measure the P-waves propagation speed (32) with a portable ultrasonic tester PUNDIT 7 model PC1012, recording 4 measurements in each specimen (1 longitudinally and 3 transversally). The Young's dynamic modulus ( $E$, in $\mathrm{GPa})$ was estimated from the average P-wave velocity $\left(\mathrm{V}_{\mathrm{P}}\right.$, in $\left.\mathrm{m} / \mathrm{s}\right)$ as follows [2] (33):

$$
E=10^{-6} \cdot \mathrm{V}_{\mathrm{P}}^{2} \cdot \rho_{\text {wet }} \cdot(1+v) \cdot(1-2 v) /(1-v)
$$

where:

TABLE 1. Properties of the aggregates. $\mathrm{MW}=$ Mineral wastes; $\mathrm{CFW}=$ Carbon fiber wastes; $\rho_{\mathrm{B}}=$ Loose bulk density; $\rho_{\mathrm{A}}=$ Particle density; $\rho_{\mathrm{S}}=$ Skeleton density; $\rho_{\text {matrix }}=$ Relative density of aggregate matrix; $\rho_{\mathrm{ssd}}=$ saturated-surface dried density; $\mathrm{WA}=$ Water absorption after $24 \mathrm{~h}$ of immersion; $P_{\mathrm{T}}=$ Total porosity; $P_{\mathrm{O}}=$ Open porosity; $P_{\mathrm{C}}=$ Closed porosity; $H=$ Void

\begin{tabular}{|c|c|c|c|c|c|c|c|c|c|c|c|c|c|c|}
\hline \multirow[b]{2}{*}{ Aggregate } & \multirow[b]{2}{*}{ Source } & \multirow[b]{2}{*}{$\begin{array}{c}\text { Size } \\
(\mathrm{mm})\end{array}$} & \multicolumn{5}{|c|}{ Density $\left(\mathrm{g} / \mathrm{cm}^{3}\right)$} & \multirow[b]{2}{*}{$\begin{array}{l}\text { WA } \\
(\%)\end{array}$} & \multicolumn{3}{|c|}{ Porosity (\%) } & \multirow[b]{2}{*}{$\begin{array}{c}H \\
(\%)\end{array}$} & \multirow[b]{2}{*}{$\begin{array}{c}S \\
\left(\mathbf{N} / \mathbf{m m}^{2}\right)\end{array}$} & \multirow[b]{2}{*}{$\begin{array}{c}S / \rho_{\mathrm{A}} \\
(\mathbf{N} / \mathbf{m} \cdot \mathbf{g})\end{array}$} \\
\hline & & & $\rho_{\mathrm{B}}$ & $\rho_{\mathrm{A}}$ & $\rho_{\mathrm{s}}$ & $\boldsymbol{\rho}_{\text {matrix }}$ & $\rho_{\text {ssd }}$ & & $\boldsymbol{P}_{\mathrm{T}}$ & $P_{\mathrm{O}}$ & $\boldsymbol{P}_{\mathrm{C}}$ & & & \\
\hline $\mathrm{CA}^{\mathrm{a}}{ }^{\mathrm{a}}$ & $\begin{array}{l}\mathrm{MW}+2.5 \% \mathrm{CFW} \\
\text { (sinter: } 1125^{\circ} \mathrm{C}, 4 \mathrm{~min} \text { ) }\end{array}$ & $8 / 10$ & 1.12 & 1.85 & 2.16 & 2.62 & 1.99 & 7.9 & 29.4 & 14.7 & 14.7 & 57.4 & 12.3 & 6.7 \\
\hline CA40 & $\begin{array}{l}\mathrm{MW}+2.5 \% \mathrm{CFW} \\
\text { (sinter: } 1140{ }^{\circ} \mathrm{C}, 4 \mathrm{~min} \text { ) }\end{array}$ & $8 / 10$ & 0.85 & 1.44 & 1.58 & 2.59 & 1.53 & 6.3 & 44.4 & 8.9 & 35.5 & 67.2 & 5.3 & 3.7 \\
\hline $\mathrm{CA50}^{\mathrm{a}}$ & $\begin{array}{l}\mathrm{MW}+2.5 \% \mathrm{CFW} \\
\left(\text { sinter: } 1150{ }^{\circ} \mathrm{C}, 4 \mathrm{~min}\right)\end{array}$ & $8 / 10$ & 0.72 & 1.13 & 1.20 & 2.57 & 1.19 & 5.0 & 55.9 & 5.7 & 50.2 & 72.0 & 3.0 & 2.7 \\
\hline $\mathbf{A X}$ & $\begin{array}{l}\text { Commercial LWA: } \\
\text { Argex AR 4/10-550 }\end{array}$ & $8 / 10$ & 0.47 & 0.82 & 1.00 & 2.64 & 1.00 & 22.0 & 68.9 & 18.0 & 50.9 & 82.2 & 1.3 & 1.5 \\
\hline NA & Achères (normal weight) & $8 / 10$ & 1.43 & 2.51 & 2.64 & 2.69 & 2.56 & 2.0 & 6.7 & 5.0 & 1.7 & 46.8 & $27.0^{\mathrm{b}}$ & $10.8^{\mathrm{b}}$ \\
\hline Sand & Sable de Seine & $0 / 4$ & 1.84 & 2.57 & 2.68 & 2.69 & 2.61 & 1.4 & 4.5 & 4.0 & 0.5 & 31.6 & $28.8^{\mathrm{b}}$ & $11.2^{\mathrm{b}}$ \\
\hline
\end{tabular}
percentage; $S=$ Single aggregate crushing strength.

${ }^{a}$ Data collected from Moreno-Maroto et al. (12)

${ }^{\mathrm{b}}$ Values of $S$ estimated from the equation that relates $S$ and $\rho_{\mathrm{A}}$ in Figure 2 (in the case of NA the individual grain strength exceeded the detection limit of the press in 13 out of 25 specimens while the size of the sand particles was too small for the test). 
$v$ is the Poisson's ratio, while the other terms have been defined previously. A value of $v=0.23$ has been considered according to ASTM STP 169D (33).

Just after, the flexural strength $\left(f_{\mathrm{F}}\right.$, in $\left.\mathrm{MPa}\right)$ was determined according to EN-196-1 (34) and the compressive strength $\left(f_{\mathrm{C}}\right.$, in $\left.\mathrm{MPa}\right)$ was also measured using the halves obtained from the flexural test. In this case, 3 compressive data were recorded, so that the other 3 intact halves along with the chunks from the compressive test were placed in an oven at $80^{\circ} \mathrm{C}$ to dry to a constant weight. Once the weight was constant, the dry density of the concrete $\left(\rho_{\text {dry }}\right.$, in $\left.\mathrm{g} / \mathrm{cm}^{3}\right)$ was calculated. Likewise, the open porosity $\left(P_{\text {con }}\right.$, in \%) was measured in one of the dry halves according to NF P18-459 (35). To do this, the concrete samples were placed inside a desiccator, which in turn was pipe-interconnected to a system comprised of two pumps and a water container, controlled by means of a valve system. Thus, once the air was removed by pumping, the concrete pieces were soaked in water under vacuum conditions for $48 \mathrm{~h}$ to ensure the complete water filling of the open pores. The thermal conductivity $(\lambda$, in $\mathrm{W} / \mathrm{m} \cdot \mathrm{K})$, the specific heat $\left(c_{\mathrm{P}}\right.$, in $\left.\mathrm{J} / \mathrm{kg} \cdot \mathrm{K}\right)$ and the thermal diffusivity $\left(\alpha\right.$, in $\left.\mathrm{mm}^{2} / \mathrm{s}\right)$ were measured in triplicate with a Hot Disk TPS 1500 equipment based on the Transient Plane Source Technique (36). A Kapton probe with a radius of $6.403 \mathrm{~mm}$ was used for this, so that this sensor was sandwiched between the two previously dried intact concrete halves to take the measurements. Some representative chunks in all the $w / c=0.45$ concrete varieties were selected, lyophilized and nickel coated under vacuum to be observed by Scanning Electron Microscopy (SEM). SEM pictures were taken using a Leica S430i Scanning Electron Microscope with tungsten filament coupled to a second electron imaging mode.
The same procedures and tests described above were also followed for the mortar samples. All the associated results are elaborated in Table 2.

In order to assess the degree of interconnection between the variables related to manufacture conditions and the technological properties, a correlation matrix has been computed. Using the IBM SPSS Statistics 22 software, a Shapiro-Wilk normality test was carried out. Based on the data obtained, a Spearman coefficient $\left(r_{\mathrm{S}}\right)$ was considered because it does not require a normal distribution. The correlations have considered as significant when $p<0.05$ and highly significant when $p<0.01$ under bilateral analysis (Table 3).

\section{RESULTS AND DISCUSSION}

\subsection{Mechanical and physical properties of the aggregates}

The results of CA25 and CA50 correspond to those already published in Moreno-Maroto et al. (12). As shown in Table 1, the normal coarse aggregate (NA) and the sand have the highest values of density $\left(\rho_{\mathrm{A}}, \rho_{\mathrm{S}}, \rho_{\text {matrix }}\right.$ and $\left.\rho_{\mathrm{ssd}}>2.5 \mathrm{~g} / \mathrm{cm}^{3}\right)$ and the lowest water absorption (WA $<2 \%$ ).

In the case of the sintered CAs, it is observed that the higher firing temperature, the lighter the specimens, meeting in all the cases the density requirement for LWA of the EN-13055-1 standard ( $\rho_{\mathrm{B}}$ less than $1.20 \mathrm{~g} / \mathrm{cm}^{3}$ or $\rho_{\mathrm{A}}$ not exceeding $\left.2.00 \mathrm{~g} / \mathrm{cm}^{3}\right)$ (2). AX is the lightest and most absorbent aggregate of those studied $\left(\rho_{\mathrm{A}}=0.82\right.$ and WA $>22 \%$ ), which means that this type of LWA has a permeable shell and an important interconnected porosity $\left(P_{\mathrm{O}}=18 \%\right)$. In the case of the CAs, WA is less than $8 \%$ despite their high porosity (more pronounced

TABLE 2. Results obtained for the concrete and mortar specimens. $\mathrm{w} / \mathrm{c}=$ water/cement ratio; $\mathrm{t}_{\mathrm{F}}=$ workability-meter test time; $\rho_{\text {wet }}=$ wet density; $\rho_{\text {dry }}=$ dry density; $f_{\mathrm{F}}=$ flexural strength; $f_{\mathrm{C}}=$ compressive strength; $\mathrm{V}_{\mathrm{P}}=\mathrm{P}$-waves transmission speed; $E=$ Young's

dynamic elastic modulus; $\lambda=$ thermal conductivity; $\alpha=$ thermal diffusivity; $c_{\mathrm{P}}=$ specific heat; $P_{\text {con }}=$ interconnected porosity.

\begin{tabular}{lllllllllllllll}
\hline Name & $\begin{array}{c}\text { Coarse } \\
\text { aggregate }\end{array}$ & $\mathbf{w / c}$ & $\begin{array}{c}\mathbf{t}_{\mathrm{F}} \\
(\mathbf{s})\end{array}$ & $\begin{array}{c}\rho_{\text {wet }} \\
\left(\mathbf{g} / \mathbf{c m}^{3}\right)\end{array}$ & $\begin{array}{c}\rho_{\text {dry }} \\
\left(\mathbf{g} / \mathbf{c m}^{3}\right)\end{array}$ & $\begin{array}{c}\boldsymbol{f}_{\mathrm{F}} \\
(\mathbf{M P a})\end{array}$ & $\begin{array}{c}\boldsymbol{f}_{\mathrm{C}} \\
(\mathbf{M P a})\end{array}$ & $\boldsymbol{f}_{\mathrm{F}} \boldsymbol{l} \boldsymbol{f}_{\mathbf{C}}$ & $\begin{array}{c}\mathbf{V}_{\mathrm{P}} \\
(\mathbf{m} / \mathbf{s})\end{array}$ & $\begin{array}{c}\boldsymbol{E} \\
(\mathbf{G P a})\end{array}$ & $\begin{array}{c}\lambda \\
(\mathbf{W} / \mathbf{m} \cdot \mathbf{K})\end{array}$ & $\begin{array}{c}\alpha \\
\left(\mathbf{m m}^{2} / \mathbf{s}\right)\end{array}$ & $\begin{array}{c}\boldsymbol{c}_{\mathbf{P}} \\
(\mathbf{J} / \mathbf{k g} \cdot \mathbf{K})\end{array}$ & $\begin{array}{c}\boldsymbol{P}_{\text {con }} \\
(\mathbf{\%})\end{array}$ \\
\hline CA25C-0.45 & CA25 & 0.45 & 8.7 & 2.15 & 1.99 & 10.0 & 54.7 & 0.18 & 4080 & 30.9 & 1.39 & 0.98 & 743.5 & 17.0 \\
CA25C-0.55 & CA25 & 0.55 & 2.6 & 2.12 & 1.94 & 8.8 & 43.9 & 0.20 & 4130 & 31.2 & 1.29 & 0.77 & 856.0 & 21.4 \\
CA40C-0.45 & CA40 & 0.45 & 5.3 & 1.99 & 1.85 & 8.6 & 43.1 & 0.20 & 4050 & 28.2 & 1.32 & 0.79 & 920.3 & 16.7 \\
CA40C-0.55 & CA40 & 0.55 & 1.8 & 1.95 & 1.79 & 7.5 & 40.5 & 0.19 & 4130 & 28.7 & 1.05 & 0.78 & 768.8 & 23.9 \\
CA50C-0.45 & CA50 & 0.45 & 4.2 & 1.91 & 1.78 & 8.2 & 37.9 & 0.22 & 4140 & 28.3 & 1.04 & 0.66 & 903.0 & 16.5 \\
CA50C-0.55 & CA50 & 0.55 & 1.2 & 1.88 & 1.73 & 7.9 & 36.4 & 0.22 & 4100 & 27.3 & 0.92 & 0.68 & 797.2 & 22.0 \\
AXC-0.45 & AX & 0.45 & 5.2 & 1.87 & 1.66 & 7.2 & 17.7 & 0.41 & 4220 & 28.7 & 1.02 & 0.70 & 922.1 & 28.6 \\
AXC-0.55 & AX & 0.55 & 1.5 & 1.78 & 1.54 & 6.0 & 14.6 & 0.41 & 4090 & 25.7 & 0.85 & 0.54 & 1022.8 & 33.4 \\
NAC-0.45 & NA & 0.45 & 7.2 & 2.39 & 2.24 & 9.9 & 54.9 & 0.18 & 4290 & 37.9 & 1.88 & 1.21 & 816.4 & 14.6 \\
NAC-0.55 & NA & 0.55 & 2.4 & 2.37 & 2.21 & 9.4 & 42.2 & 0.22 & 4320 & 38.1 & 1.92 & 1.27 & 686.1 & 14.7 \\
MT-0.45 & None & 0.45 & 1.5 & 2.29 & 2.09 & 9.3 & 54.2 & 0.17 & 4100 & 33.2 & 1.67 & 1.17 & 702.9 & 19.1 \\
MT-0.55 & None & 0.55 & 0.8 & 2.25 & 2.02 & 8.5 & 42.9 & 0.20 & 4120 & 32.9 & 1.79 & 1.04 & 882.4 & 21.8 \\
\hline
\end{tabular}




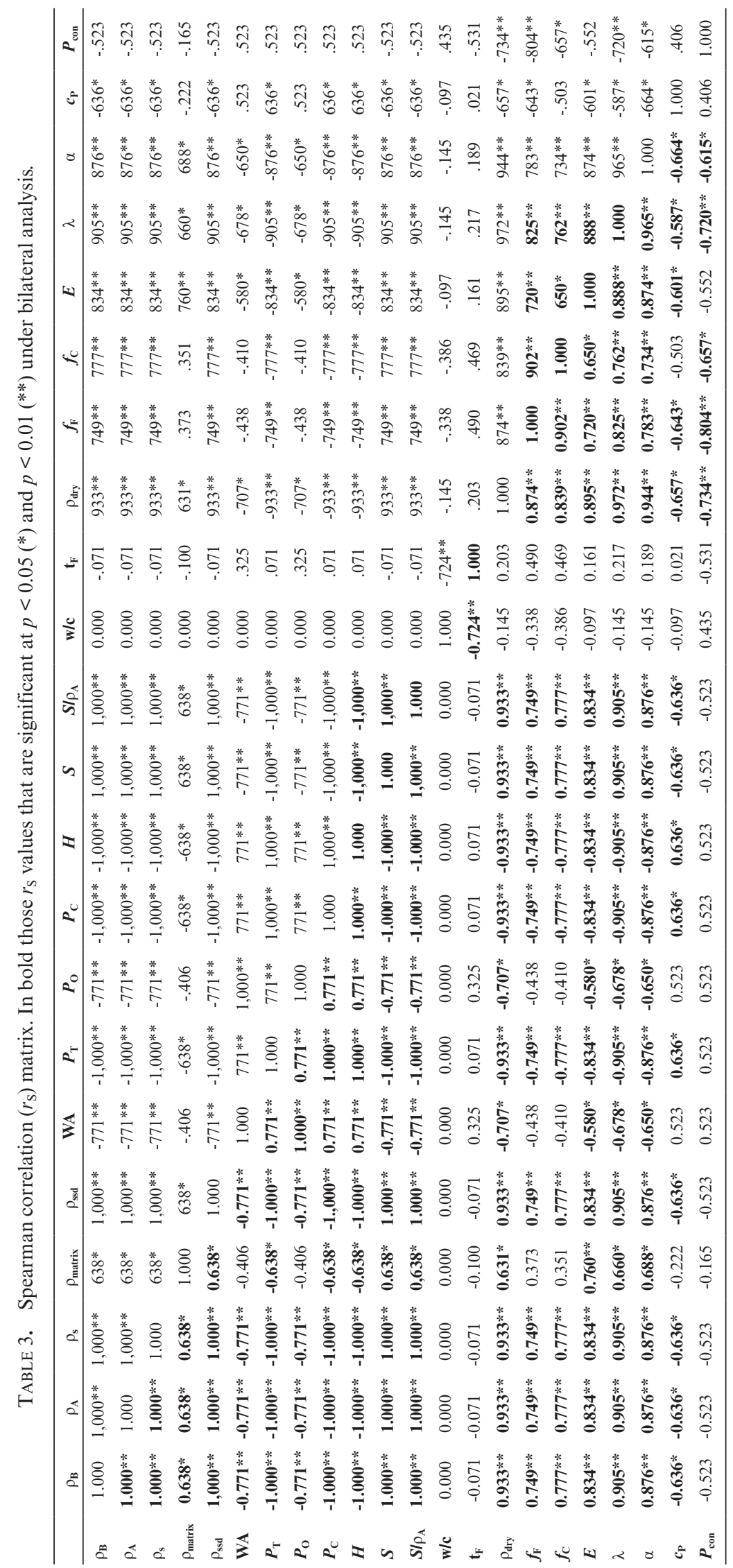


in CA40 and CA50, with $P_{\mathrm{T}}$ values of $44.4 \%$ and $55.9 \%$ respectively), which would be due to the presence of an almost watertight shell and/or a low interconnection between the inner pores $\left(P_{\mathrm{O}}\right.$ is less than $9 \%$ in CA40 and CA50) (12).

As can be observed in both Table 1 and Figure 2, there is a clear relationship between the density of the aggregates and their single crushing strength $(S)$, such that $S$ increases potentially as the density becomes higher. Therefore, AX is significantly weaker than the CAs, especially when compared toCA25 (1.3 MPa vs 12.3 MPa with a standard deviation, sd, of 0.6 and 2.5 respectively). In the case of NA, the crushing test was completed on just 12 out of 25 specimens, recording a mean value of 14.5 $\mathrm{MPa}$, so that the other 13 yielded values over the press detection limit. Relying on the equation shown in Figure 2, which relates $\rho_{\mathrm{A}}$ with $S$, the estimated $S$ value of NA would be $27.0 \mathrm{MPa}$. Similarly, the sand would have an estimated crushing strength of $28.8 \mathrm{MPa}$.

Therefore, the main factors affecting the mechanical strength would be: 1) the amount, distribution and size of the pores $(25), 2$ ) the thickness of the outer shell $(12,25,37), 3)$ the presence of unburnt carbon fibers embedded in the aggregate core, which has been demonstrated to exert an extra reinforcement on the internal structure (12) and 4) the degree of sintering of the aggregate matrix, which is enhanced by the addition of carbon fiber (12). These characteristics are visually illustrated in Figure 3, which includes two SEM pictures of Moreno-Maroto et al. (12) with detailed views of the shell and the inner pores of CA25 and CA50 (Figure 3a,b), as well as one picture of how the carbon fibers are embedded within the CA40 aggregate in the form of individual fibers and bunches (Figure 3c). Regarding the first premise related to porosity, according to the $r_{\mathrm{S}}$ coefficients shown in Table 3, the density drops directly as $P_{\mathrm{T}}$ increases, which is translated into lower results of $S$ and $S / \rho_{\mathrm{A}}$.

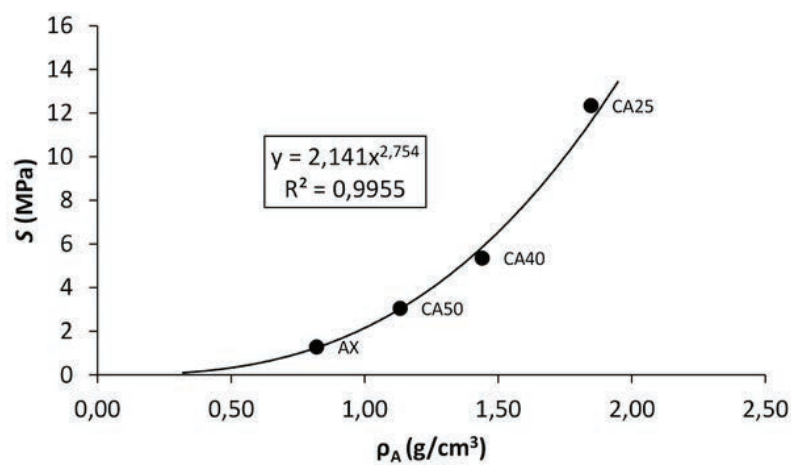

FIGURE 2. Relationship between the single aggregate crushing strength $(S)$ of the LWAs and their respective particle densities $\left(\rho_{\mathrm{A}}\right)$. (a)

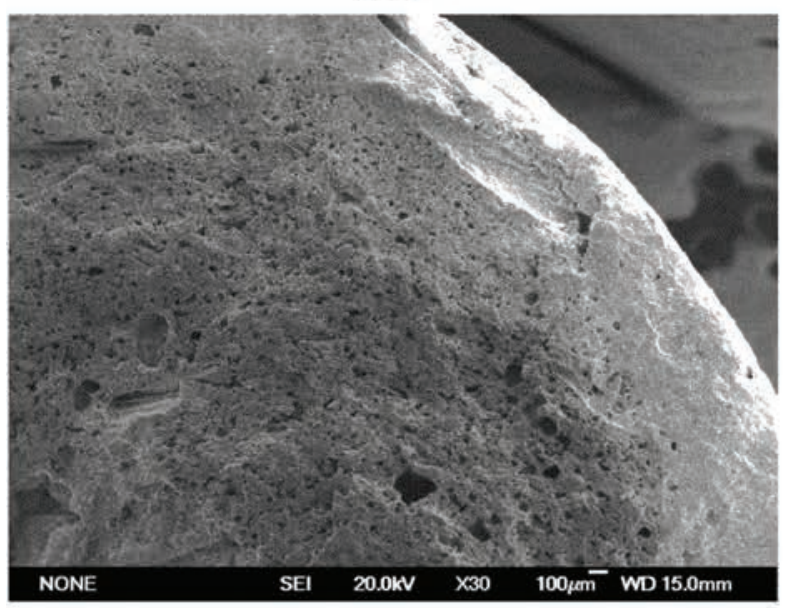

(b)

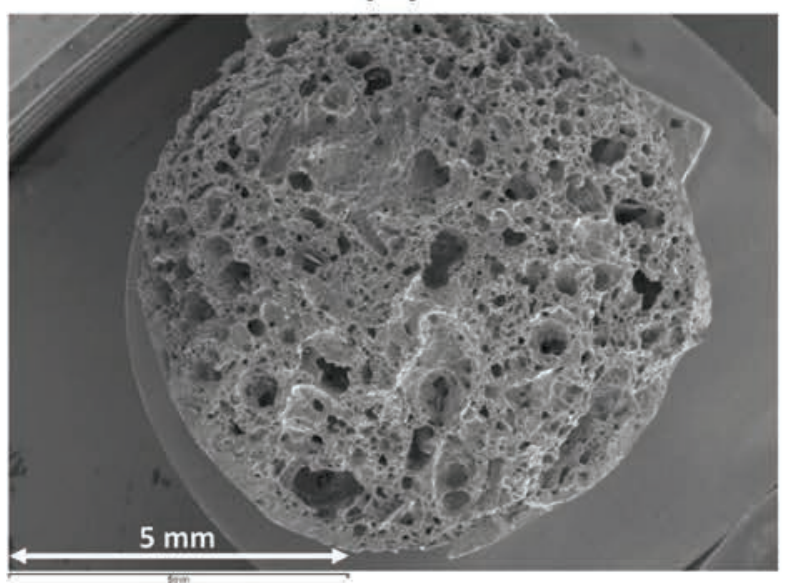

(c)

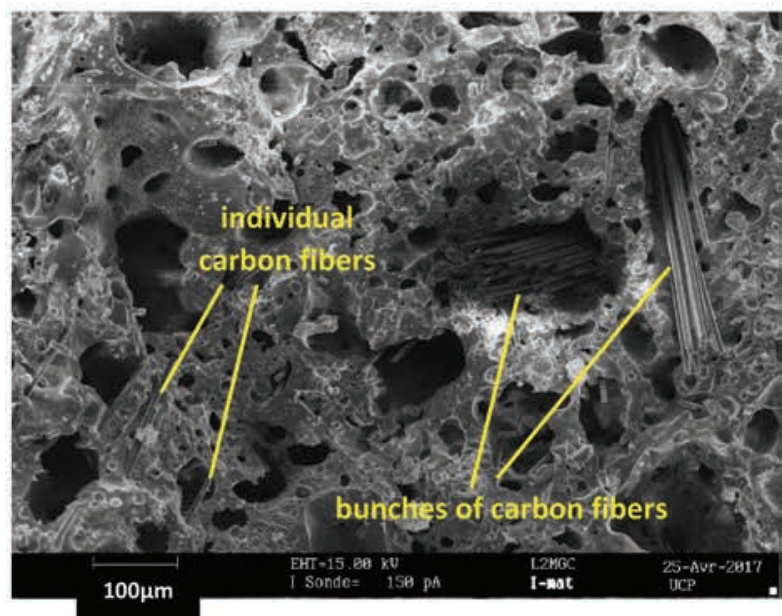

FIGURE 3. Scanning Electron Microscopy pictures of: (a) shell-core section of CA25 (from Moreno-Maroto et al. (12)), (b) total cross section of CA50 (from Moreno-Maroto et al. (12)), (c) detail view of bunches and individual carbon fibers embedded in the core of CA40. 
For its part, the $S / \rho_{\mathrm{A}}$ ratio represents the balance between mechanical strength and density of the individual aggregates, acting as a good indicator of the suitability of LWA for concrete (38). The low crushing strength of CA50, and particularly of AX, makes them show the lowest $S / \rho_{\mathrm{A}}$ ratios, with results lower than those recorded in the commercial LWA "Leca Strutturale" $\left(S / \rho_{\mathrm{A}}=3.46 \mathrm{~N} / \mathrm{m} \cdot \mathrm{g}\right.$ and $\left.S=4.5 \mathrm{MPa}\right)$, which is intended for structural concrete (38).

\subsection{Influence of the type of aggregate on the workability, density and porosity of the concrete}

Each concrete variety has been designated according to the following code:

$\mathrm{XC}-\mathrm{Z}$

where: $\mathrm{X}$ is the name of the coarse aggregate, $\mathrm{C}$ means concrete and $\mathrm{Z}$ takes the values 0.45 or 0.55 depending on the w/c ratio used. In the case of the mortar, XC is merely replaced by the term MT.

The data of $t_{F}$ are represented in Table 2. As expected and in accordance with the correlations in Table 3, the fluidity is greater $\left(t_{F}\right.$ is shorter) with $\mathrm{w} / \mathrm{c}=0.55\left(\mathrm{t}_{\mathrm{F}}\right.$ between $0.8 \mathrm{~s}$ and $\left.2.6 \mathrm{~s}\right)$ if compared with $\mathrm{w} / \mathrm{c}=0.45\left(\mathrm{t}_{\mathrm{F}}\right.$ between $1.5 \mathrm{~s}$ and $\left.8.7 \mathrm{~s}\right)$ in all cases. In fact, the fresh samples prepared with $\mathrm{w} / \mathrm{c}=0.55$ were too liquid, while those manufactured with $\mathrm{w} / \mathrm{c}=0.45$ held a proper workability according to their $t_{F}$ values (31). The fluidity varied depending on the type of aggregate, so the longer the $t_{F}$, the lower the flow capacity. Thus, $\mathrm{t}_{\mathrm{F}}$ decreased in the following order: $\mathrm{CA} 25 \mathrm{C}>\mathrm{NAC}>>\mathrm{CA} 40 \mathrm{C}=\mathrm{AXC}>\mathrm{CA}$ $50 \mathrm{C}>>>\mathrm{MT}$. These results indicate that the fluidity is increased when the coarse aggregates are absent (MT is the most flowing) and the aggregates tend to be lighter. Thus, two different concrete groups can be distinguished, on one side, the two heaviest varieties, CA25C and NAC, with $t_{F}$ values of 8.7 and $7.2 \mathrm{~s}$, respectively, and, on the other side, the three lightest, CA40C, CA50C and AXC, whose $t_{F}$ range from 4 to $5 \mathrm{~s}$. Accordingly, the fluidity seems to increase when the aggregate density decreases. For aggregates of similar density, the very close $t_{F}$ values show that the effective w/c ratio has been well controlled during the manufacture of the concrete.

On the other hand, probably the main objective when designing LWAC is to achieve lightness. According to the results detailed in Table 2 and Figure 4, all the samples prepared with both CAs and AX have a dry density $\left(\rho_{\text {dry }}\right)$ lower than $2.0 \mathrm{~g} / \mathrm{cm}^{3}$, meeting the requirements stipulated for LWAC (3). AXC presents the lowest density (1.54 and $1.66 \mathrm{~g} /$ $\left.\mathrm{cm}^{3}\right)$, followed by CA50C $\left(1.73\right.$ and $\left.1.78 \mathrm{~g} / \mathrm{cm}^{3}\right)$, CA40C (1.79 and $\left.1.85 \mathrm{~g} / \mathrm{cm}^{3}\right)$ and CA25C (1.94 and $\left.1.99 \mathrm{~g} / \mathrm{cm}^{3}\right)$. The MT specimens take $\rho_{\mathrm{dry}}$ values of 2.02 and $2.09 \mathrm{~g} / \mathrm{cm}^{3}$ while NAC results are 2.21 and $2.24 \mathrm{~g} /$ $\mathrm{cm}^{3}$. As can be observed graphically in Figure 4, the variation in the w/c ratio has barely affected the density, so a very small decrease in density is obtained when more water is added. Therefore, the main factor affecting the final density of the cured concrete in this study is not the $\mathrm{w} / \mathrm{c}$ ratio, but the density of the coarse aggregate, as reflected by the strong linear correlations obtained when plotting $\rho_{\text {dry }}$ against $\rho_{\mathrm{A}}$ in Figure 5 , in agreement with the data in Table 3 as well.

Another factor affecting concrete density is porosity, which in turn influences other properties such as strength, shrinkage, creep, durability, permeability and ionic diffusion (33). The parameter here measured, $P_{\text {con }}$, is related to the interconnected porosity, which mainly influences the last three aspects mentioned. Therefore, greater values of $P_{\text {con }}$ could entail the transport of deleterious ionic species (such as chlorides and sulfates) towards the interior of the concrete structure, affecting the rates of physical and chemical deterioration (33). Hence, it would be expected that the open porosity of the aggregates $\left(P_{\mathrm{O}}\right.$; Table 1$)$ could affect $P_{\text {con }}$, as the results of Table 2 reflect: $P_{\text {con }}$ exhibits similar values in MT, CA25C, CA40C and CA50C $\left(P_{\text {con }}\right.$ data

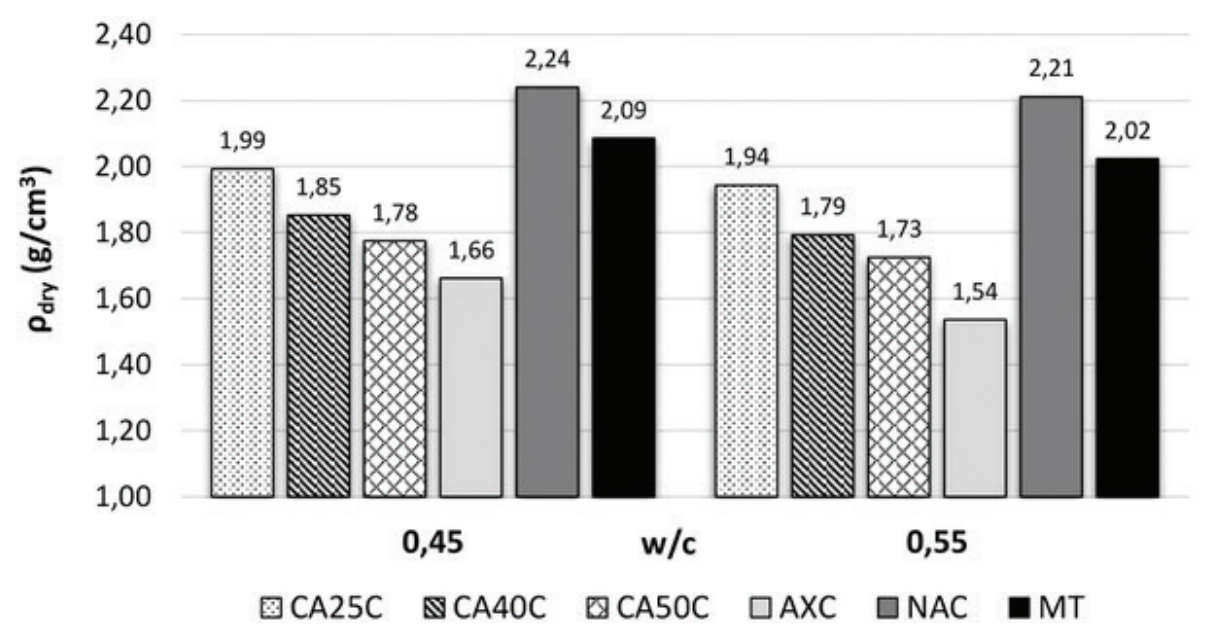

FIGURE 4. Density of the concrete and mortar in the dry state $\left(\rho_{\text {dry }}\right)$ for the corresponding w/c ratios of 0.45 and 0.55 . 


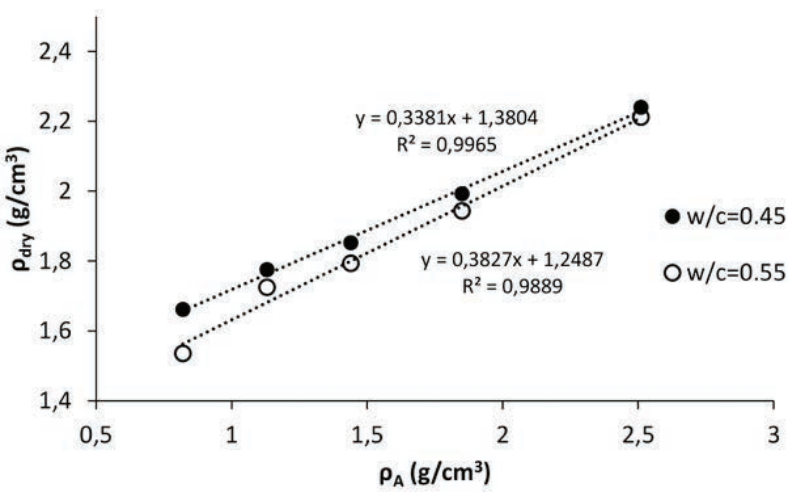

FIGURE 5. Relationship between the dry density of the concrete $\left(\rho_{\text {dry }}\right)$ and the particle density $\left(\rho_{\mathrm{A}}\right)$ of the coarse aggregates for the w/c ratios studied.

around $17-19 \%$ when $w / c=0.45$ and $21-22 \%$ with w/c $=0.55$, all of them with an aggregate $P_{\mathrm{O}}$ lower than $8 \%$, except CA25). On the contrary, $P_{\text {con }}$ presents its lowest result in the heaviest concrete specimen (NAC- $0.45, P_{\text {con }}=14.6 \%$ ), whose $P_{\mathrm{O}}$ is very low $(5 \%)$ and its highest value in the lightest one (AXC$0.55, P_{\text {con }}=33.4 \%$ ), which likewise exhibits the greatest $P_{\mathrm{O}}(18 \%)$. The fact that the $\mathrm{w} / \mathrm{c}=0.55$ ratio fosters an increase of $P_{\text {con }}$ over w/c $=0.45$ (Table 2 ) is in line with the literature (33).

\subsection{Mechanical properties of the concrete}

\subsubsection{Compressive strength, flexural strength and Young's modulus}

Just as density is a key parameter in LWAC, the mechanical strength is too, so a good balance between these two properties is usually required to get a suitable LWAC. The results obtained on $f_{\mathrm{C}}, f_{\mathrm{F}}$ and $E$ are summarized in Table 2 and graphically depicted in Figure 6.

Regarding $f_{\mathrm{F}}$, this parameter tends to rise slightly as the proportion of cement is higher (Figure 6a). In general, $f_{\mathrm{F}}$ ranges between $6 \mathrm{MPa}$ (AXC-0.55) and $10 \mathrm{MPa}$ (CA25C-0.45) with an average standard deviation of 0.6 , increasing in the following order according to the aggregate used in each case: $\mathrm{AXC}<<\mathrm{CA} 50 \mathrm{C}<\mathrm{CA} 40 \mathrm{C}<\mathrm{MT}<\mathrm{CA} 25 \mathrm{C}<\mathrm{NAC}$, although the results are almost overlapped around $10 \mathrm{MPa}$ in the concrete containing CA25 and normal aggregates when w/c is 0.45 .

With respect to $f_{\mathrm{C}}$, the results of Table 2 are plotted in Figure 6b, whose standard deviations have an average value of 3.8. AXC has a very low compressive strength (between 14 and $18 \mathrm{MPa}$ ), whereas in the case of the CACs, average $f_{\mathrm{C}}$ values of around 35,40 and $50 \mathrm{MPa}$ have been obtained when using the CA50, CA40 and CA25 aggregates, respectively (even up to $55 \mathrm{MPa}$ in CA25C-0.45). This indicates that concrete made with CAs is not only much stronger than those made with AX, but can also be used for structural purposes (4). In fact, it should be emphasized that the results of $f_{\mathrm{C}}$ in $\mathrm{CA} 25 \mathrm{C}$ are essentially the same as those of the mortar and the normal concrete (Figure 6b), according to the following sequence: AXC $<<<$ CA50C $<$ CA40C $<$ $<\mathrm{MT}=\mathrm{NAC}=\mathrm{CA} 25 \mathrm{C}$. Concerning the w/c ratio, significant enhancements in $f_{\mathrm{C}}$ have been achieved only in the MT, NAC and CA25C specimens by decreasing the water content in the fresh mixture (Figure 6b). The lack of sensitivity of the strength to the w/c ratio in $\mathrm{CA} 40 \mathrm{C}, \mathrm{CA} 50 \mathrm{C}$ and $\mathrm{AXC}$ is explained by the fact that the coarse aggregate is presumably the weakest component in these samples and, therefore, this element defines the overall mechanical performance, an aspect that will be further elaborated in the next section.

The variation in the results would be linked to the individual crushing strength $(S)$ of the aggregates, as indicated by the significant correlations between $f_{\mathrm{C}}, f_{\mathrm{F}}$ and $S$ in Table 3 , which is also tied to the density and porosity of the aggregates. Furthermore, as explained above, the fact that the new CAs present carbon fibers within their structure (Figure 3c) could be an additional factor that enhances the aggregate strength (12) and, consequently, the strength of the concrete cast with them.

Based on the data from $V_{P}$ (whose average sd is 44.2) and $\rho_{\text {wet }}$ (average sd of 0.01 ), $E$ has been estimated as indicated in Eq. 2, so that the $E$ results range from $38.1 \mathrm{GPa}$ (NAC-0.55) to 25.7 (AXC$0.55)$, according to the following rough order: $\mathrm{AXC}=\mathrm{CA} 50 \mathrm{C}=\mathrm{CA} 40 \mathrm{C}<\mathrm{CA} 25 \mathrm{C}<\mathrm{MT}<\mathrm{NAC}$ (Table 2 and Figure $6 \mathrm{c}$ ). The correlations of Table 3 suggest that, as in the case of $f_{\mathrm{C}}$ and $f_{\mathrm{F}}$, the dynamic elastic modulus, $E$, increases with the crushing strength of the aggregates, $S$, demonstrating again that it plays an important role affecting the mechanical properties of the concrete.

\subsubsection{Macroscopic and SEM analysis of fracture areas}

Some representative fracture surface pictures taken right after the flexural and compressive tests are shown in Figure 7. Even though the specimens shown in Figure 7 correspond only to w/c $=0.45$, the same failure characteristics have been observed when the w/c ratio of 0.55 was used. Likewise, as the surface of the flexural failure is "cleaner" than that of the compressive test, all the pictures in Figure 7, except Figure $7 \mathrm{~g}$, are related to the flexural cross sections in order to have clearer images. In any case, the fracture produced will be interpreted jointly because it has similar characteristics.

Focusing only on the aggregates, in the case of AXC in Figure 7d (the concrete made up of the LWA with the lowest $S$ ), the fracture occurs by total breakage across the aggregates. Besides this, a significant segregation is observed in AXC due to the 
(a)

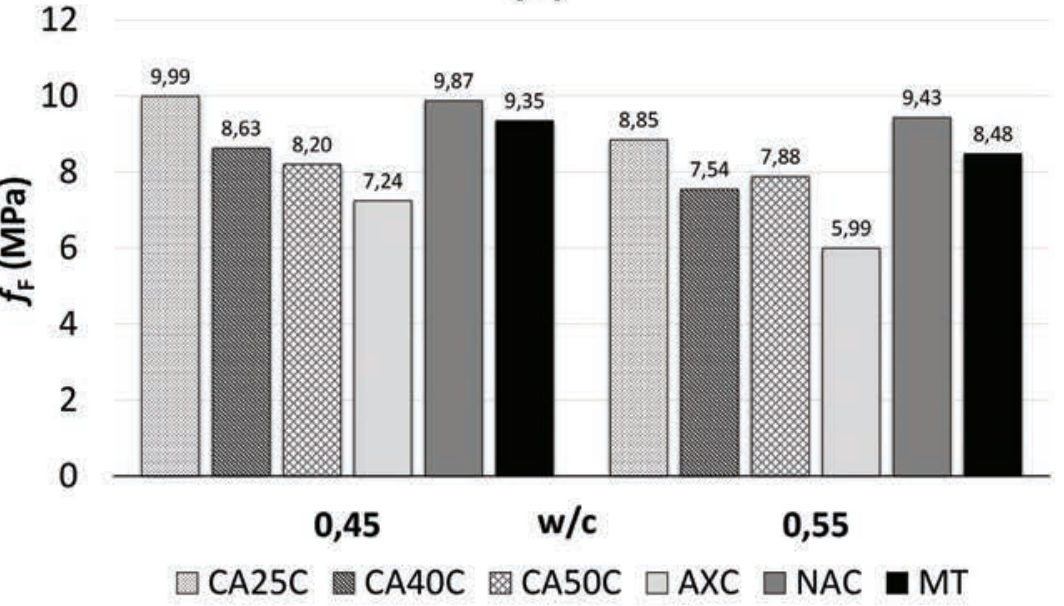

(b)

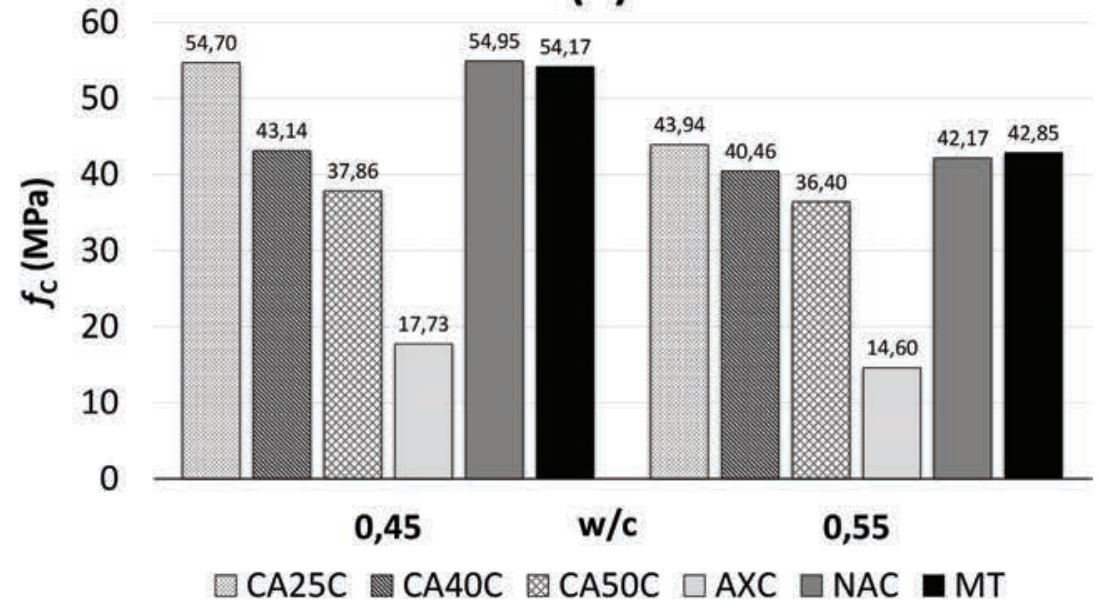

(c)

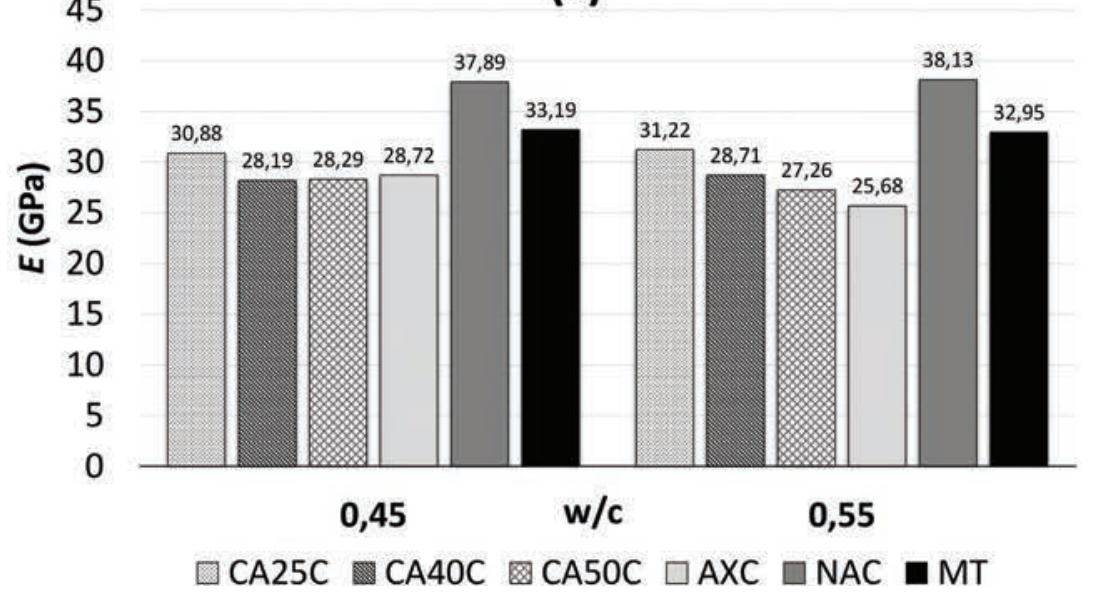

Figure 6. Results of (a) flexural strength, $f_{\mathrm{F}}$, (b) compressive strength, $f_{\mathrm{C}}$, and (c) dynamic elastic modulus, $E$, obtained in the concrete and mortar specimens. 
(a)

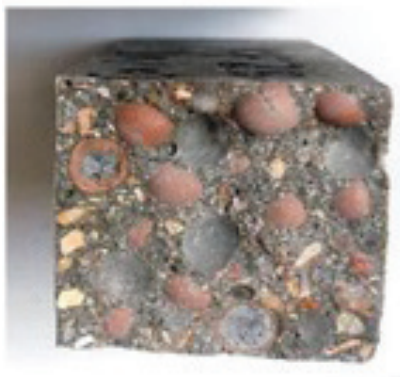

(e)

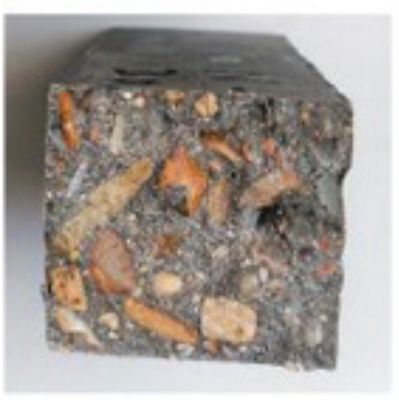

(b)

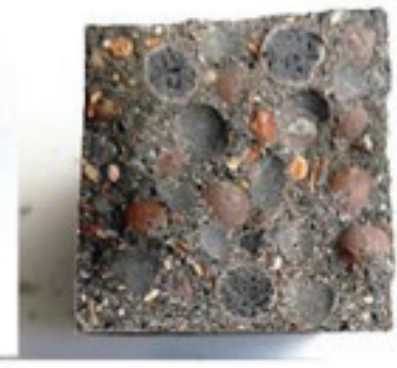

(c)

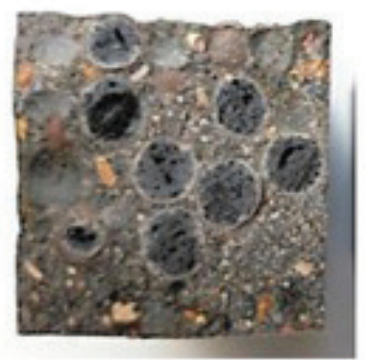

(d)

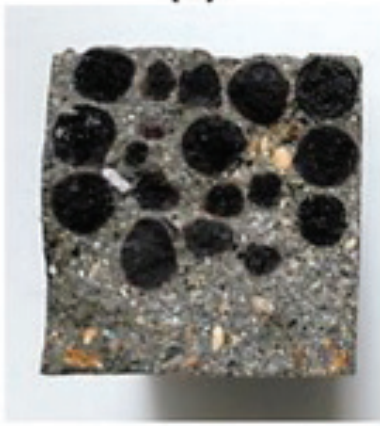

(g)
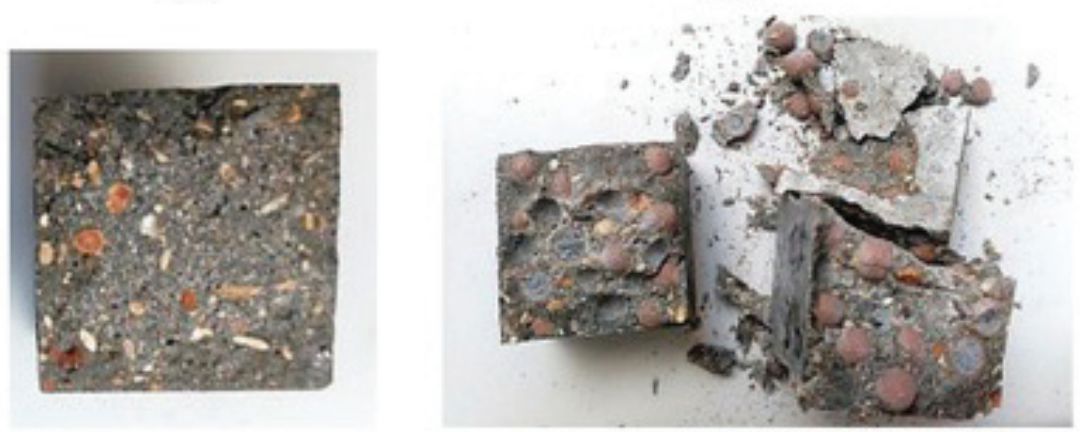

Figure 7. Internal section after flexural test in one half of (a) CA25C-0.45, (b) CA40C-0.45, (c) CA50C-0.45, (d) AXC-0.45, (e) NAC-0.45, (f) MT-0.45 and (g) fragments obtained after the compressive strength in one specimen of CA25C-0.45.

low density of the coarse aggregate, which tended to move towards the surface during the compaction stage (Figure 7d).

Conversely, in the CACs, as the aggregate is heavier and more resistant, the segregation is reduced, and the failure tends to take place along the aggregate surface without breaking them (5). Thus, in CA50C (Figure 7c) although the failure occurs across the aggregate, there are some undamaged LWAs, increasing the number of these in CA40C (Figure 7b), and finally almost all the aggregates are able to withstand the applied stress in CA25C (Figure 7a,g), either compressive or flexural, as occurs with the normal concrete samples (Figure 7e). This last aspect is an ultimate indicator that in CA25C and NAC, the mortar strength (Figure 7f), its $E$ and the quality of the interfacial transition zone (ITZ) would be the limiting factors that determine the $f_{\mathrm{C}}$ to be achieved, while for the rest of samples, this depends on the strength of the coarse aggregate $(5,39)$.

In addition to being related to the individual strength of the aggregates, the compressive and flexural strength, $f_{\mathrm{C}}$ and $f_{\mathrm{F}}$, would depend to a large extent on the strength of the bonds between the aggregate and the cement (5), or in other words, on the characteristics of the abovementioned ITZ. As can be seen in the SEM images in Figure 8, with the exceptions of CA50C (Figure 8c) and especially
AXC (Figure 8d), some areas at which the ITZ is actually a gap have been detected in all the samples (Figure 8 a,b,e,f). Here there is not contact between the aggregate and the cement and therefore these zones are weaker than others. This would be attributed to a very smooth and low permeable outer surface of the aggregates, which would reduce the paste-aggregate bond strength. In the case of AXC, the roughness and high open porosity of the aggregate surface could have enabled better contact with the cement and the ingress of water with cement particles into the aggregate (40), improving the properties of the ITZ. Because of its significant porosity, the deformability of the AX aggregate is presumably greater than that of the other varieties. So, a better elastic compatibility between the matrix and the aggregates and a smaller and less porous ITZ probably explain that there is no crack in the matrix-aggregate interface $(41,42)$. Indeed, the transgranular cracks pattern observed in AXC confirms the good bond strength between the paste and AX aggregate, which is corroborated by the higher $f_{\mathrm{F}} / f_{\mathrm{C}}$ ratio (Table 2 ) of $\mathrm{AXC}(0.41)$ compared to the other concretes (around 0.2). Despite this, the low mechanical strength of the AX aggregates was translated into the lowest $f_{\mathrm{C}}$ and $f_{\mathrm{F}}$ results. Therefore, in those concretes with more porous aggregates (CA40C, CA50C and especially AXC), the weakest component is not the interfacial transition zone 
(a)

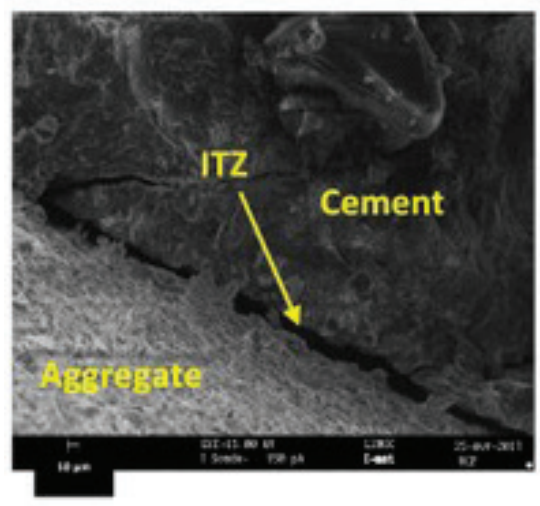

(d)

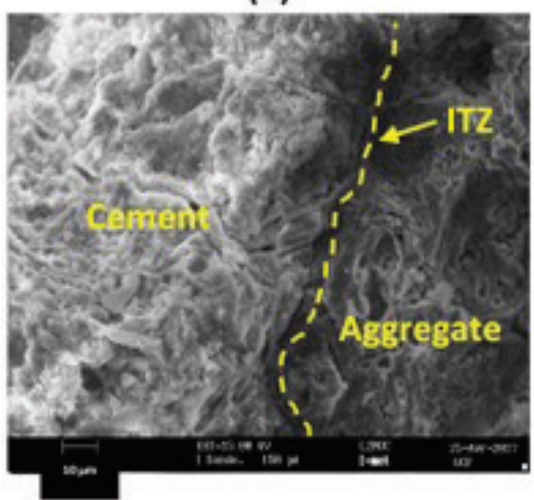

(b)

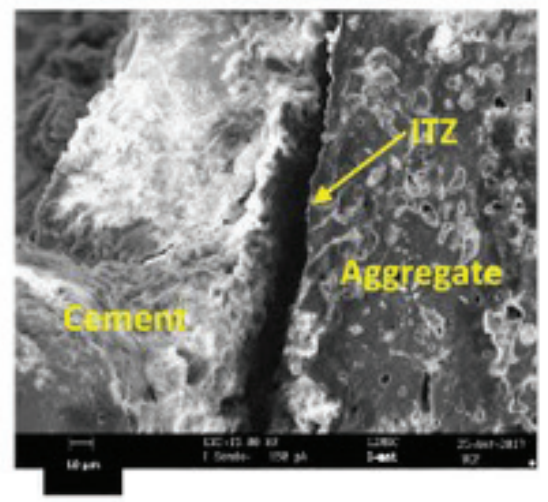

(e)

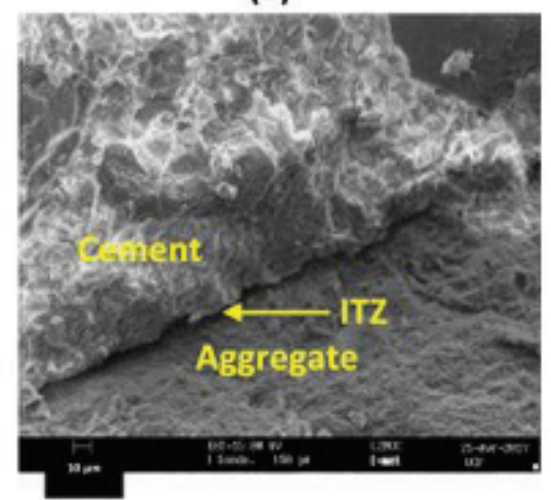

(c)

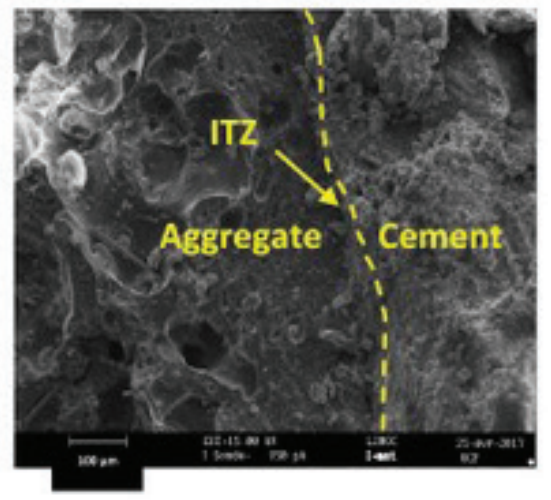

(f)

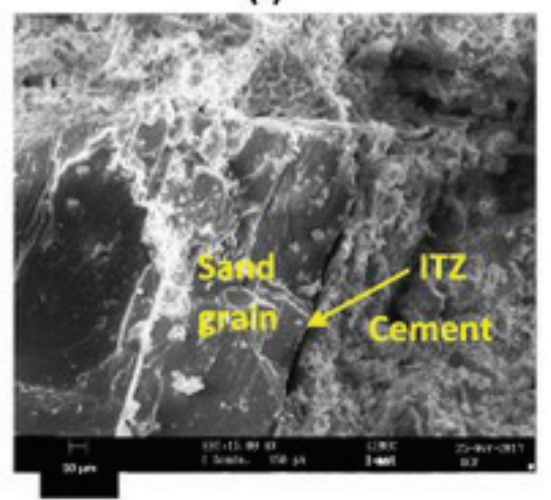

FIGURE 8. Detailed Scanning Electron Microscope pictures of the interfacial transition zone (ITZ) existing between the aggregates and the cement paste in some selected fragments from: (a) CA25C-0.45, (b) CA40C-0.45, (c) CA50C-0.45,

(d) AXC-0.45, (e) NAC-0.45, (f) MT-0.45. Dotted lines have been drawn to delimit the ITZ in (c) and (d) because ITZ is not as clear in them as in the rest of samples.

(ITZ) or the cementitious matrix, but the aggregate, and consequently, the mechanical performance of the studied LWAC are not controlled by the quality of the cementitious matrix or the ITZ (as occurred in CA25C and NAC), but by the mechanical properties of the LWA, as shown by the fracture path travelled through the aggregates in Figure 7.

\subsection{Thermal properties of the concrete}

The results of thermal conductivity, $\lambda$, specific heat, $c_{\mathrm{P}}$, and thermal diffusivity, $\alpha$, are shown in Table 2. According to the Spearman coefficients of Table $3, \lambda$ and $\alpha$ are directly correlated with each other, so they follow similar trends. In the case of $c_{\mathrm{P}}$, its correlation with $\lambda$ and $\alpha$ is less pronounced, and the trend would be the opposite: $c_{\mathrm{P}}$ would increase when the other two parameters decrease. This concurs with the expected physical properties determined by each one according to the following expression: $\alpha=\lambda /\left(\rho_{\mathrm{dry}} \cdot c_{\mathrm{P}}\right)$, because the Hot Disk TPS 1500 equipment measures $\lambda$ and $\alpha$ firstly and then computes $c_{\mathrm{P}}$ taking density into account.
Therefore, the values of $\lambda$ and $\alpha$ increase according to this sequence: NAC $>\mathrm{MT}>>$ CA25C $>$ CA40C $>>$ CA50C $>$ AXC, while the $c_{\mathrm{P}}$ one follows an approximately opposite order.

Focusing on $\lambda$ to study the insulating potential of the concrete, the differences observed are really significant depending on the type of aggregate used, which is clearer in Figure 9. In the case of NAC and $\mathrm{MT}$, the parameter $\lambda$ ranges between 1.7 and $1.9 \mathrm{~W} / \mathrm{m} \cdot \mathrm{K}$, approximately. The use of LWAs has improved the results of $\lambda$, so that its value is less than $1.4 \mathrm{~W} / \mathrm{m} \cdot \mathrm{K}$ in all the LWAC specimens. The data from CA40C-0.55 $(\lambda=1.05 \mathrm{~W} / \mathrm{m} \cdot \mathrm{K})$, CA50C$0.55(\lambda=0.92 \mathrm{~W} / \mathrm{m} \cdot \mathrm{K})$ and CA50C-0.45 $(\lambda=1.04$ $\mathrm{W} / \mathrm{m} \cdot \mathrm{K})$ must be stood out as being quite similar to those from AXC-0.55 and AXC-0.45 $(\lambda=0.85$ and $1.02 \mathrm{~W} / \mathrm{m} \cdot \mathrm{K}$, respectively). This means that these CAC samples have an improved insulating capacity.

These enhancements would be directly connected to the density of the concrete, so the lighter, the better the insulation, as reflected in the high $r_{\mathrm{S}}$ coefficients when relating $\lambda$ to the $\rho_{\text {dry }}\left(r_{\mathrm{S}}=0.972\right.$ in Table 3$)$. As indicated in previous sections, the drop in density 


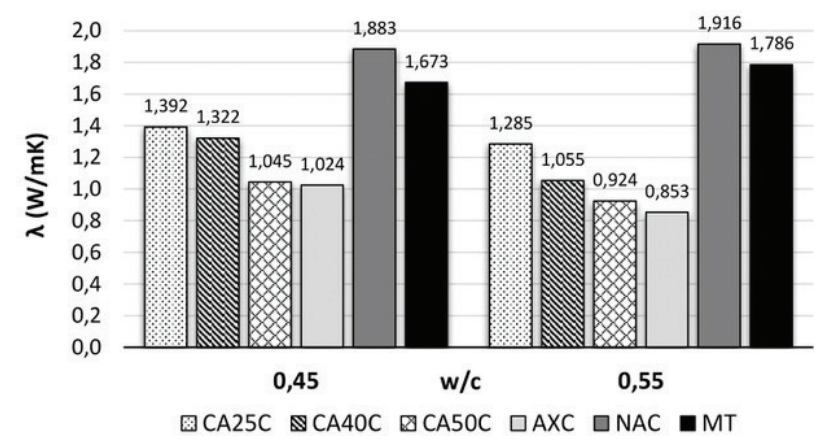

FIGURE. 9. Thermal conductivity $(\lambda)$ results obtained in the concrete and mortar specimens for the corresponding $\mathrm{w} / \mathrm{c}$ ratios of 0.45 and 0.55 .

would be mainly attributed to a more porous structure of the aggregates, while the w/c ratio and $P_{\text {con }}$ would affect to a lesser extent. Thus, the porosity of the aggregates is probably the main factor affecting the concrete insulation capacities, because more energy is needed to increase the temperature of the air or the water filling the pores than that of the solid phase (36). Another aspect that could influence thermal transfer is the mineralogy of the aggregates, so that some differences could be attributed to this factor. However, a rigorous quantitative mineralogical analysis (including an accurate calculation of the amorphous phase by advanced XRD methods) would be required to know this properly, something that exceeds the scope of the present study.

\subsection{Selection of concrete according to optimal characteristics.}

All the possible relationships between $f_{\mathrm{C}}, \rho_{\text {dry }}$ and $\lambda$ are detailed in Table 4 .

The analysis of these ratios will allow the selection of the best concrete specimens according to their mechanical, density and thermal properties, as detailed below:

- $\quad f_{\mathrm{C}} / \rho_{\text {dry }}:$ It represents the relationship between compressive strength and density of concrete. The new CACs present ratios between 21 and $27 \mathrm{~N} / \mathrm{m} \cdot \mathrm{g}$, which are in the same order or even over the results obtained in NAC and MT, and well above that of AXC $(10 \mathrm{~N} / \mathrm{m} \cdot \mathrm{g})$. The decrease in w/c clearly improves the $f_{\mathrm{C}} \rho_{\text {dry }}$ ratio for NAC and CA25C whose aggregates are the strongest. For the other aggregates, the enhancement of the paste strength only leads to a low increase of the concrete strength. The tensile strength of the aggregates is another limiting factor of LWAC's strength.

- $f_{\mathrm{C}} / \lambda$ :This new ratio relates compressive strength to thermal conductivity. In this case, the best results are all those coming from the concrete manufactured using the new CAs, with results between 32-40 $\mathrm{MN} \cdot \mathrm{K} / \mathrm{m} \cdot \mathrm{W}$, which are higher
TABLE 4. Relationship between the results of $f_{\mathrm{C}}, \rho_{\mathrm{dry}}$ and $\lambda$.

\begin{tabular}{lcccc}
\hline Name & $\begin{array}{c}\boldsymbol{f}_{\mathrm{C}} / \boldsymbol{\rho}_{\text {dry }} \\
(\mathbf{N} / \mathbf{m} \cdot \mathbf{g})\end{array}$ & $\begin{array}{c}\boldsymbol{f}_{\mathrm{C}} / \boldsymbol{\lambda} \\
(\mathbf{M N} \cdot \mathbf{K} / \mathbf{m} \cdot \mathbf{W})\end{array}$ & $\begin{array}{c}\mathbf{1} / \boldsymbol{\rho}_{\text {dry }} \cdot \lambda \\
\left(\mathbf{m}^{4} \cdot \mathbf{K} / \mathbf{g} \cdot \mathbf{M W}\right)\end{array}$ & $\begin{array}{c}\boldsymbol{f}_{\mathrm{C}} / \boldsymbol{\rho}_{\text {dry }} \cdot \boldsymbol{\lambda} \\
\left(\mathbf{N} \cdot \mathbf{m}^{2} \cdot \mathbf{K} / \mathbf{g} \cdot \mathbf{W}\right)\end{array}$ \\
\hline CA25C-0.45 & 27.45 & 39.30 & 0.36 & 19.72 \\
$\mathbf{C A 2 5 C - 0 . 5 5}$ & 22.61 & 34.18 & 0.40 & 17.59 \\
$\mathbf{C A 4 0 C - 0 . 4 5}$ & 23.29 & 32.64 & 0.41 & 17.62 \\
$\mathbf{C A 4 0 C - 0 . 5 5}$ & 22.56 & 38.36 & 0.53 & 21.39 \\
$\mathbf{C A 5 0 C - 0 . 4 5}$ & 21.33 & 36.24 & 0.54 & 20.42 \\
$\mathbf{C A 5 0 C - 0 . 5 5}$ & 21.10 & 39.40 & 0.63 & 22.84 \\
AXC-0.45 & 10.67 & 17.31 & 0.59 & 10.42 \\
AXC-0.55 & 9.51 & 17.12 & 0.76 & 11.15 \\
NAC-0.45 & 24.53 & 29.17 & 0.24 & 13.02 \\
NAC-0.55 & 19.07 & 22.01 & 0.24 & 9.95 \\
MT-0.45 & 25.98 & 32.37 & 0.29 & 15.52 \\
MT-0.55 & 21.18 & 23.99 & 0.28 & 11.86 \\
\hline
\end{tabular}

than those of NAC and MT, and again significantly higher than those of AXC.

- $1 / \rho_{\text {dry }} \lambda \lambda$ : High values of this new parameter emphasize low values of density and thermal conductivity. As expected, the best results correspond to the lightest samples: AXC, CA50C and $\mathrm{CA} 40 \mathrm{C}-0.55$, with ratios around 0.55 and $0.75 \mathrm{~m}^{4} \cdot \mathrm{K} / \mathrm{g} \cdot \mathrm{MW}$.

- $\quad f_{\mathrm{C}} / \rho_{\mathrm{dry}} \cdot \lambda$ : It is also an innovative ratio developed in the present investigation. This is probably the most representative of the four presented, since it includes the three variables, so that the compressive strength is relativized with respect to the density and the thermal conductivity of the concrete. Here, again, the best results correspond to those of the new CACs, with values around $20-23 \mathrm{~N} \cdot \mathrm{m}^{2} \cdot \mathrm{K} / \mathrm{g} \cdot \mathrm{W}$, which are clearly higher than those of the mortar, the normal concrete and the specimens manufactured with AX (results between $10-15 \mathrm{~N} \cdot \mathrm{m}^{2} \cdot \mathrm{K} / \mathrm{g} \cdot \mathrm{W}$ ).

Therefore, from a general perspective, the best concretes developed in this study according to the balance between the mechanical, density and thermal transfer characteristics, would be those manufactured with the new carbon fiber aggregates following this order (in bold those specimens which are classified as LWAC according to their low density):

CA50C-0.55 $>$ CA40C-0.55 $>$ CA50C-

$$
\begin{gathered}
\text { 0.45 }>\text { CA25C }-0.45>\text { CA40C-0.45 }>\text { CA25C- } \\
\mathbf{0 . 5 5}>>\text { MT }-0.45>\text { NAC }-0.45>\text { MT }-0.55 \\
>\text { AXC }-0.55>\text { AXC }-0.45>\text { NAC }-0.55
\end{gathered}
$$

\section{CONCLUSIONS}

Three new lightweight aggregates containing carbon fiber (CAs) have been studied as coarse components in lightweight aggregate concrete (LWAC). 
Prismatic concrete specimens of $40 \times 40 \times 160 \mathrm{~mm}^{3}$ with w/c ratios of 0.45 and 0.55 were manufactured and subjected to a complete analysis of their mechanical and physical properties. Likewise, other specimens with a normal weight aggregate (NA), a commercial LWA (here referred to as AX) and mortar (MT) were cast for comparison.

The CAs were obtained according to a previous study of the authors (12): spherical pellets were prepared from a mixture of $97.5 \%$ of fine-grained mineral wastes and $2.5 \%(\mathrm{w} / \mathrm{w})$ of powdered carbon fiber scraps. The CAs were manufactured by sintering the pellets at 1125,1140 and $1150{ }^{\circ} \mathrm{C}$, obtaining the varieties designated here as CA25, CA40 and CA50, respectively. The use of these three different firing temperatures allowed different characteristics to be obtained in the CAs: thus, the temperature increase was related to lower values of both density and individual crushing strength due to the formation of pores and to a greater combustion of the fibers.

Comparing the different aggregates tested, a clear relationship between the density (related in turn to porosity) and the mechanical strength was observed. AX exhibited the lowest values of density and single particle crushing strength, while NA the opposite. The new CAs had intermediate characteristics in this regard, but always meeting the requirements established for LWAs.

The properties measured in the concrete samples were directly linked to those of the aggregates, so that other factors, such as the w/c ratio, barely affected the characteristics beyond the fluidity. Focusing on the new carbon fiber lightweight aggregate concretes (CACs), all the specimens have displayed low dry densities $\left(1.73-1.99 \mathrm{~g} / \mathrm{cm}^{3}\right)$ and low thermal conductivities $(0.9-1.4 \mathrm{~W} / \mathrm{m} \cdot \mathrm{K})$, some of them similar to those of AXC, which indicates their suitability as lightweight insulating materials. In addition, the CACs exhibit good mechanical properties taking into account the results of $f_{\mathrm{C}}$, $f_{\mathrm{F}}$ and $E$. In fact, the compressive strength, $f_{\mathrm{C}}$, has ranged from around $35 \mathrm{MPa}$ to $55 \mathrm{MPa}$, like those obtained in NAC and MT. This would indicate that the innovative CACs could be used for structural purposes, while the commercial AXC would be very limited in this regard $\left(f_{\mathrm{C}}<20 \mathrm{MPa}\right)$, despite the latter holding an ITZ with better bonds than that of the CACs.

According to the ratios that interrelate $f_{\mathrm{C}}, \rho_{\mathrm{dry}}$ and $\lambda$, the new CACs presented the highest ratios between the mechanical and physical properties, especially those specimens containing the aggregates CA50 and CA40. This would be attributed to the characteristics of the CAs, which are, on the one hand, very light due to its high porosity, but on the other hand, quite strong because of the carbon fiber additive, which reinforces the internal structure of the aggregate due to: 1) the presence of strong carbon fibers embedded within the aggregate and 2) the intense sintering that occurs when the carbon fiber is thermally treated, fostering the development of both a thick strong shell and a porous but resistant core (12).

In conclusion, according to the outcome of this investigation, the new lightweight aggregates containing carbon fiber should be considered as feasible and suitable components for that lightweight concrete in which not only lightness or thermal insulation is sought, but also high mechanical strength.

\section{ACKNOWLEDGEMENTS}

This research has been mainly supported by the research project PEII-2014-025-P of the Junta de Comunidades de Castilla-La Mancha (JCCM), the $\mathrm{PhD}$ grant number PRE-7911/2014 whose funds come from the Consejería de Educación, Cultura y Deportes of JCCM and the European Social Fund (DOCM 2014/10620 and DOCM 2016/12998 BDNS (Identif.): 323799.), and the grant received from the University of Castilla-La Mancha intended to stays in foreign centers (DOCM 2016/11635). A special thanks to the Erasmus + framework for its additional support.

\section{REFERENCES}

1. Weinecke, M.H.; Faulkner, B.P. (2002) Production of lightweight aggregate from waste materials. Min. Eng. 54 [11], $39-43$.

2. EN-13055-1 (2002) Lightweight aggregates. Part 1: Lightweight aggregates for concrete, mortar and grout. European Committee for Standardization.

3. EN 206-1 (2000) Concrete. Part 1: Specification, performance, production and conformity. European Committee for Standardization.

4. EHE-08 (2008) Instrucción de Hormigón Estructural (EHE-08). Ministerio de Fomento, Gobierno de España.

5. Gerritse, A. (1981) Design considerations for reinforced lightweight concrete. Int. J. Cem. Compos. Lightweight Concrete. 3 [1], 57-69. https://doi.org/10.1016/ 0262-5075(81)90031-2

6. Torres, P.; Fernandes, H.R.; Olhero, S.; Ferreira, J.M.F. (2009)Incorporation of wastes from granite rock cutting and polishing industries to produce roof tiles. J. Eur. Ceram. Soc. 29[1], 23-30. https://doi.org/10.1016/j. jeurceramsoc.2008.05.045

7. Dondi, M.; Cappelletti, P.; D'Amore, M.; de Gennaro, R.; Graziano, S.F.; Langella, A.; Raimondo, M.; Zanelli, C. (2016) Lightweight aggregates from waste materials: Reappraisal of expansion behavior and prediction schemes for bloating. Constr. Build. Mater. 127, 394 409. https:// doi.org/10.1016/j.conbuildmat.2016.09.111

8. Lynn, C.J.; Dhir, R.K.; Ghataora, G.S.; West, R.P. (2015) Sewage sludge ash characteristics and potential for use in concrete. Constr. Build. Mater. 98, 767-779. https://doi. org/10.1016/j.conbuildmat.2015.08.122

9. Wainwright, P.J.; Cresswell, D.J.F. (2001) Synthetic aggregates from combustion ashes using an innovative rotary kiln. Waste Manage. 21 [3], 241-246. https://doi. org/10.1016/S0956-053X(00)00096-9

10. De' Gennaro, R.; Langella, A.; D' Amore, M.; Dondi, M.;Colella, A.; Cappelletti, P.; De' Gennaro, M. (2008) Use of zeolite-rich rocks and waste materials for the production of structural lightweight concretes. Appl. 
Clay Sci. 41, 61-72. https://doi.org/10.1016/j.clay.2007. 09.008

11. Mueller, A.; Schnell, A.; Ruebner, K. (2015) The manufacture of lightweight aggregates from recycled masonry rubble. Constr. Build. Mater. 98, 376-387. https://doi. org/10.1016/j.conbuildmat.2015.07.027

12. Moreno-Maroto, J.M.; González-Corrochano, B.; Alonso-Azcárate, J.; Rodríguez, L.; Acosta, A. (2017) Manufacturing of lightweight aggregates with carbon fiber and mineral wastes. Cem. Concr. Compos. 83, 335-348. https://doi.org/10.1016/j.cemconcomp.2017.08.001

13. Fitzer, E. (1987) The future of carbon-carbon composites. Carbon. 25[2], 163-190. https://doi. org/10.1016/0008-6223(87)90116-3

14. Tanyildizi, H. (2008) Effect of temperature, carbon fibers, and silica fume on the mechanical properties of lightweight concretes. New Carbon Mater., 23[4], 339-344. https://doi. org/10.1016/S1872-5805(09)60005-6

15. Park, S.B.; Lee, B.I. (1993) Mechanical Properties of Carbon-Fiber-Reinforced Polymer-Impregnated Cement Composites. Cem. Concr. Compos. 15[3], 153-163. https:// doi.org/10.1016/0958-9465(93)90004-S

16. Zheng, Q.; Chung, D.D.L. (1989) Carbon fiber reinforced cement composites improved by using chemical agents. Cem. Concr. Res. 19[1], 25-41. https://doi. org/10.1016/0008-8846(89)90062-8

17. Garcés, P.; Fraile, J.; Vilaplana-Ortego, E.; CazorlaAmorós, D.; Alcocel, E.G.; Andión, L.G. (2005) Effect of carbon fibres on the mechanical properties and corrosion levels of reinforced portland cement mortars. Cem. Concr. Res. 35[2], 324-331. https://doi.org/10.1016/j. cemconres.2004.05.013

18. Chen, B.; Liu, J.; Wu, K. (2005) Electrical responses of carbon fiber reinforced cementitious composites to monotonic and cyclic loading. Cem. Concr. Res. 35[11], 2183-2191. https://doi.org/10.1016/j.cemconres.2005.02.004

19. Mingqing, S.; Zhuoqiu, L.; Qizhao, M.; Darong, S. (1999) A study on thermal self-monitoring of carbon fiber reinforced concrete. Cem. Concr. Res. 29[5], 769-771. https:// doi.org/10.1016/S0008-8846(99)00006-X

20. Fu, X.; Chung, D.D.L. (1995) Contact electrical resistivity between cement and carbon fiber: Its decrease with increasing bond strength and its increase during fiber pull-out. Cem. Concr. Res. 25[7], 1391-1396. https://doi. org/10.1016/0008-8846(95)00132-V

21. Yasuda, Y. (1991) Sewage-sludge utilization in Tokyo. Water Sci. Technol. 23 [10-12], 1743-1752. https://doi. org/10.2166/wst.1991.0629

22. González-Corrochano, B.;Alonso-Azcárate, J.; Rodas, M. (2009) Production of lightweight aggregates from mining and industrial wastes. J. Environ. Manag. 90 [8], 28012812. https://doi.org/10.1016/j.jenvman.2009.03.009

23. EN-1097-3 (1998) Tests for mechanical and physical properties of aggregates. Part 3: Determination of loose bulk density and voids. European Committee for Standardization.

24. EN-1097-6 (2000) Tests for mechanical and physical properties of aggregates. Part 6: Determination of particle density and water absorption. European Committee for Standardization.

25. Bernhardt, M.; Tellesbø, H.; Justnes, H.; Wiik, K. (2013) Mechanical properties of lightweight aggregates. J. Eur. Ceram. Soc. 33, 2731-2743. http://dx.doi.org/10.1016/j. jeurceramsoc.2013.05.013

26. De Santiago Buey, C.; Raya García, M. (2008) Análisis del peso específico y porosidad de materiales porosos mediante picnometría de helio. Ing. civil, ISSN 0213-8468, 151, 95-103.
27. Moreno-Maroto, J.M.; González-Corrochano, B.; AlonsoAzcárate, J.; Rodríguez, L.; Acosta, A. (2017) Development of lightweight aggregates from stone cutting sludge, plastic wastes and sepiolite rejections for agricultural and environmental purposes. J. Environ. Manage. 200, 229-242. http:// dx.doi.org/10.1016/j.jenvman.2017.05.085

28. Li, Y.; Wu, D.; Zhang, J.; Chang, L.; Fang, Z.; Shi, Y. (2000) Measurement and statistics of single pellet mechanical strength of differently shaped catalysts. Powder Technol. 113 [1-2], 176-184. https://doi. org/10.1016/S0032-5910(00)00231-X

29. Yashima, S.; Kanda, Y.; Sano, S. (1987) Relationship between particle size and fracture energy or impact velocity required to fracture as estimated from single particle crushing. Powder Technol. 51, 277-282. https://doi. org/10.1016/0032-5910(87)80030-X

30. NF P18-452 (2017) Bétons - Mesure du temps d'écoulement des bétons et des mortiers au maniabilimètre. Association Francaise de Normalisation AFNOR.

31. RILEM (2002) Workability and Rheology of Fresh Concrete: Compendium of Tests. Report of RILEM Technical Committee TC 145-WSM. Workability of Special Concrete Mixes, 54-56.

32. ASTM C 597-16 (2016) Standard Test Method for Pulse Velocity Through Concrete. Annual Book of ASTM Standards, ASTM International, West Conshohocken, PA.

33. ASTM STP 169D (2006) Significance of Tests and Properties of Concrete and Concrete-Making Materials, ASTM International, West Conshohocken, PA

34. EN-196-1 (2005) Methods of testing cement. Part 1: Determination of strength. European Committee for Standardization.

35. NF P18-459 (2010) Béton - Essai pour béton durci - Essai de porosité et de masse volumique. Association Francaise de Normalisation AFNOR.

36. Nguyen, L.H.; Beaucour, A-L.; Ortola, S.; Noumowé, A. (2014) Influence of the volume fraction and the nature of fine lightweight aggregates on the thermal and mechanical properties of structural concrete. Constr. Build. Mater. 51, 121-132. https://doi.org/10.1016/j. conbuildmat.2013.11.019

37. Ke, Y.; Beaucour, A-L.; Ortola, S.; Dumontet, H.; Cabrillac, R. (2009) Influence of volume fraction and characteristics of lightweight aggregates on the mechanical properties of concrete. Constr. Build. Mater. 23, 2821-2828. https://doi. org/10.1016/j.conbuildmat.2009.02.038

38. De' Gennaro, R.; Cappelletti, P.; Cerri, G.; De' Gennaro, M.; Dondi, M.; Graziano, S.F.; Langella, A. (2007) Campanian Ignimbrite as raw material for lightweight aggregates. Appl. Clay Sci. 37[1-2], 115-126. https://doi. org/10.1016/j.clay.2006.11.004

39. Hobbs, C. (1964) The physical properties of lightweight aggregates and concretes. Chemistry and Industry. April 11, 1964, 594-600.

40. Lo, T.Y.; Cui, H.Z. (2004) Effect of porous lightweight aggregate on strength of concrete. Mater. Lett. 58 [6] 916-919. https://doi.org/10.1016/j.matlet.2003.07.036

41. Wasserman, R.; Bentur, A. (1996) Interfacial interactions in lightweight aggregate concretes and their influence on the concrete strength. Cem. Concr. Compos. 18 [1], 67-76. https://doi.org/10.1016/0958-9465(96)00002-9

42. Ke, Y.; Ortola, S.; Beaucour, A-L.; Dumontet, H. (2010) Identification of microstructural characteristics in lightweight aggregate concretes by micromechanical modelling including the interfacial transition zone (ITZ). Cem. Concr. Res. 40 [11], 1590-1600. https://doi.org/10.1016/j. cemconres.2010.07.001 